\title{
LIII. On an integrating anemometer
}

\section{Walter Baily M.A.}

To cite this article: Walter Baily M.A. (1884) LIII. On an integrating anemometer, Philosophical Magazine Series 5, 17:108, 482-487, DOI: 10.1080/14786448408627544

To link to this article: http://dx.doi.org/10.1080/14786448408627544

册 Published online: 08 Jun 2010.

Submit your article to this journal $\pi$

LII Article views: 2

Q View related articles $₫$ 
the want of sphericity of the earth's form, and on account of the centrifugal pressure towards the equator. Extra-terrestrial influences, such as the conjunction and apposition of the sun and moon and the variation in solar radiation, are asymmetrical, so that the earth's crust heaves and cracks and allows the eutectic melted alloy to break through, and as an intrusive mass metamorphose and overlie the older formations. Once rendered asymmetrical, the geographical features give rise to climates and weathers, and determine the formation of the sedimentary strata.

LIII. On an Integrating Anemometer. By Walter Bally, M.A.*

[Plates XIV. \& XV.]

ON June 10th, 3882, I communicated to the Society a design for an integrating anemometer, and exhibited a working model $\dagger$. I have now to describe the instrument itself, which I have had made by Messrs. Elliott, with the assistance of a grant from the Royal Society. The mechanical part of the instrument is seen in perspective in Plate XIV. fig. 1. The base is of iron, and the rest of the instrument is chiefly of brass. On the base stand four columns $\mathrm{C}$, of which only two are shown in fig. 1. These hold a table $O$, of which fig. 2 gives a view as seen from above. The tops of the columns $\mathrm{C}$ are seen in fig. 2. The table supports four columns, $\mathrm{D}$, of which only two are shown in fig. 1 , and of all of which the positions are shown in fig. 2 . The pillars $D$ hold the supports of a spindle A, fig. 1, which is to be connected with a vane. There is another spindle, $B$, which is to be connected with Robinson's cups, and which turns, by means of cogs, the large horizontal disk $X$, so that $X$ will revolve with a velocity which may be taken as proportional to that of the wind. The spindle $A$ carries a horizontal bar $G$, which is to be kept by the vane in the direction of the wind, and which, by means of a forked end, holds a vertical pin rising from the centre of the bar $F$. This bar is pivoted at $\mathrm{E}$ to the centres of two trucks $\mathrm{H}$, each of which runs by means of five wheels (U) between tramlines (M) placed so as to form a cross with the arms directed towards the cardinal points (compare figs. 1 and 2). The centre of the cross is vertically over the centre of the disk $X$. Centrally between the tram-lines $M$ are slits $S$ through the table $O$. The object in having five wheels (U) placed as shown in fig. 1 (see also fig. 3) is to enable each wheel of the truck $H$

* Communicated by the Physical Society. Read December 8, 1883.

† Phil. Mag. Sept, 1882 ; Phys. Soc. Proc. vol. v. p. 157. 
Phil. Mag. S. 5. Vol . 17 . Pl. XIV.

Fig. 3 .

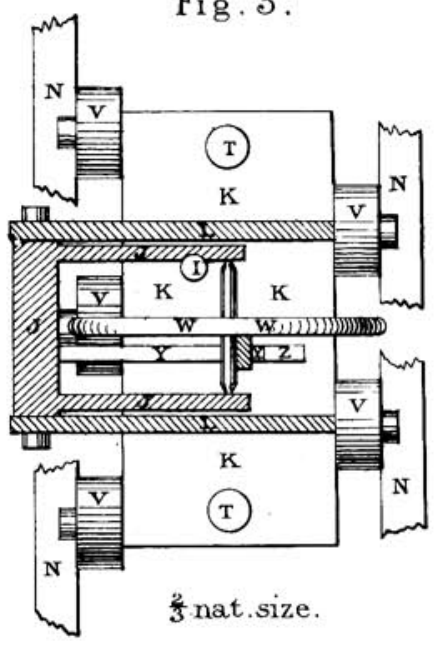

Fig. 4 .

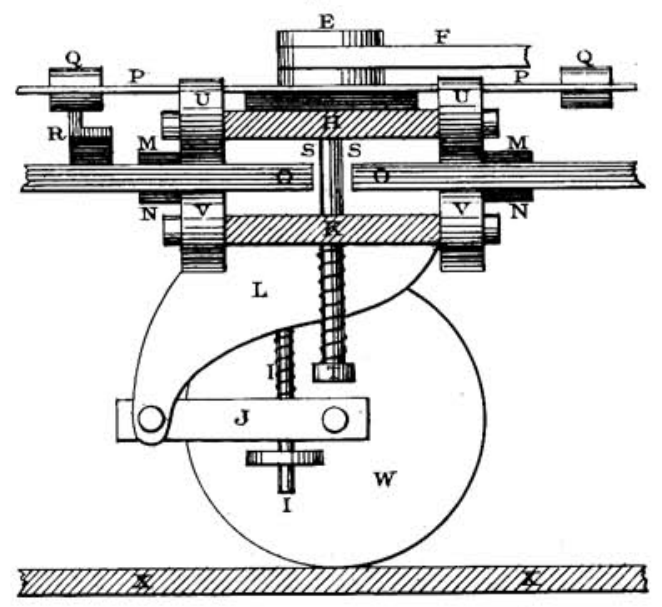

$\frac{2}{3}$ nat. size.
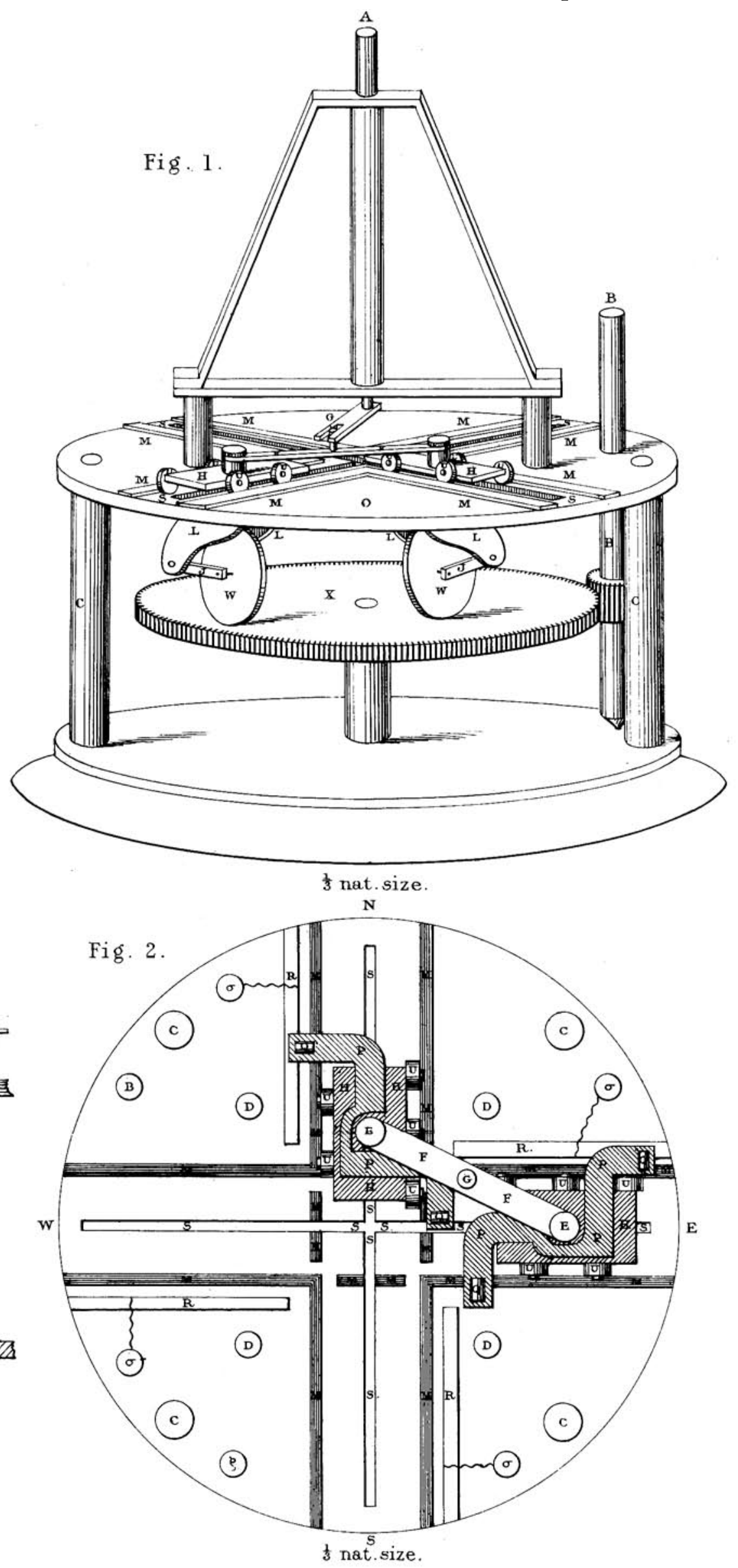
to pass over the slits $\mathrm{S}$, and yet always to keep the pivot $\mathrm{E}$ well within the base formed by the remaining four wheels, so that it may be perfectly steady. On the underside of the table $\mathrm{O}$ are similar tram-lines, $\mathrm{N}$; and trucks $(\mathrm{K})$ run in these tram-lines, each on five wheels, V. Fig. 3 shows one of these trucks seen from below, with portions of the tram-lines N.

Fig. 4 is an elevation showing an end view of the trucks $H$ and $K$, with a portion of a section of the table $O$ across a slit S. I'wo rods, T, of which the ends are shown in fig. 3, and of one of which a side view is shown in fig. 4 , are rigidly connected with $\mathrm{H}$ and pass through the slit $\mathrm{S}$ and through holes in $K$. Spiral springs surrounding the rods $T$ and resting on the heads of the rods press $K$ upwards, and make it keep its position exactly and firmly under $H$. Fach truck, $K$, carries firmly fastened to it two pieces of brass, L (see figs. 1, $3,4)$; and between these pieces is pivoted a bar with arms $J$, and between these arms is pivoted a wheel $W$, which is carried in a vertical position also at right angles to the slit through which $\mathrm{T}$ passes. A rod I connected with $\mathrm{K}$ is surrounded by a spiral spring which presses on $J$, and so keeps a steady pressure between the wheel $W$ and the disk $X$. The pivots of $\mathrm{J}$ and $W$ are so placed that, when $W$ touches $X$, these pivots all lie in one horizontal plane, and the point of contact of $W$ with $X$ is vertically below the centre of the pivot $E$ (figs. 1, 2).

Now suppose the wind to lie between North and East, and the direction from which it blows to make an angle $\theta$ with North. Let $\Omega$ be the velocity of the wind. Then the resolved parts of the wind towards North and East will be $\Omega \cos \theta$ and $\Omega \sin \theta$ respectively. But if $\delta$ be the length of the bar $F$ (fig. 2) measured between the centres of its pivots $E$, it is easily seen, from the diagram in the margin, that the distances of the wheels $W$ from the centre of the disk $X$ (fig. 1) are $\delta \cos \theta$ and $\delta \sin \theta$ towards the North and East respectively. Now the speeds of the wheels $W$ are proportional to the speed of the disk $\mathrm{X}$ on which they roll multiplied by these distances, and the speed of the disk $X$ is proportional to the velocity $\Omega$ of the wind. Hence the speeds of the wheels $\mathrm{W}$ are proportional to $\delta \cos \theta . \Omega$ and $\delta \sin \theta . \Omega$ respectively; that

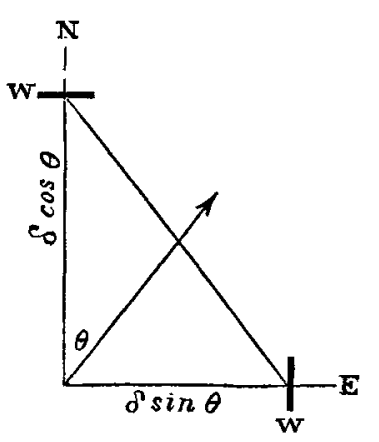
is, they are proportional to $\Omega \cos \theta$ and $\Omega \sin \theta$, which are the resolved parts of the velocity of the wind. 
If, now, we were to add a mechanical counter to each of the wheels $W$, the increase of the readings of these counters would give the integral of the resolved parts of the wind towards the North and East; and inasmuch as the wheels W revolve in the contrary direction when they have passed across the centre of the disk X, South winds would act on the counters as negative North, and West winds as negative East. Two counters would be sufficient, as a preponderance of South wind would be indicated by a decrease in the reading of the North counter, and a preponderance of West wind by a decrease in that of the East counter.

It was found, however, much more convenient to make each wheel $W$ complete an electric circuit at each revolution, and to use an electric counter; but inasmuch as such a counter will not distinguish in which direction the wheel is turning, it was necessary to have separate counters for North and South, and to shunt the circuit from one counter to the other as the wheel $W$ crossed the centre of the disk $X$, and to make a similar arrangement for East and West.

I will now describe the electric system adopted:-Parallel with the tram-lines $M$ (fig. 2) are insulated rails $R$, one of which is seen in section in fig. 4 . Each rail, $\mathrm{R}$, is connected by an insulated wire with an insulated binding-screw $\sigma$. Each truck, $\mathrm{H}$, bears a thin insulated plate of brass, $\mathrm{P}$, seen in face in fig. 2 and edgeways in fig. 3 ; and each end of the plate $P$ carries a small wheel, $Q$. At any moment, except when the truck is passing the centre of the cross, one of the wheels $Q$ rests on a rail $R$, and the other is in the air. This is clearly seen in fig. 3. At the moment when one of the trucks $H$ (say the North and South one) passes, say, from North to South across the centre, the wheel $Q$ on the North rail $R$ runs off it, and the other wheel $Q$ rans on to the South rail $R$, so that the plate $P$ of the truck is always in electrical connexion with the binding-screw $\sigma$ belonging to the cardinal point towards which the truck lies. The rails $\mathbf{R}$ bave for their upper edge a thin rail of platinum. This was added to the broad rail of brass, as it was found that points of dust or corrosion sometimes made accidental breaks in the electrical contact between $R$ and $Q$. In the truck $K$ which runs below $H$ are two parallel tongues $Y, Z$, very near one another (see fig. 3, in which the full length of $Y$ is seen, but only the end of $Z$ ). Both are fixed to $\mathrm{J}$; but $\mathrm{Z}$ is also insulated from $\mathrm{J}$, and is connected by an insulated wire, which passes through the slit $S$ (fig. 4) and through a nole in $\mathrm{H}$, with the insulated plate $\mathrm{P}$. The tongue $\mathrm{Y}$ is electrically connected with $\mathrm{K}$, and so through various points of contact with the table $O$. There is a pro- 
jection from the axle of the wheel $W$ (fig. 3 ), which once in every turn of the wheel pushes against the tongue $\mathrm{Y}$ and brings it into contact with the tongue $\mathrm{Z}$. On the table $\mathrm{O}$ (fig. 2 ) is another binding-screw $\rho$, which is not insulated. Now suppose a truck $H$ to be upon the North arm of the cross. Its tongue $\mathrm{Z}$ is in electric connexion with the North binding-screw $\sigma$, and the whole of that part of the system is insulated from the table $O$, Every time the wheel $W$ turns round, contact is made between $\mathrm{Y}$ and $\mathrm{Z}$; and the effect is that the North $\sigma$ is put into electrical connexion with the table $\mathrm{O}$, and therefore with the binding-screw $\rho$. The general electrical system is shown in Plate $X V$., which gives a front view of the box of counters, and a diagram of the anemometer, batteries, and wires. The box contains four counters lettered according to the cardinal points, and from the bindingscrews on one side (the right in the figure) insulated wires pass to the corresponding insulated binding-screws $\sigma$ on the anemometer. From the binding-screws on the other side of the box of counters insulated wires also proceed. The North and South wires are connected with one pole of a battery, and the East and West wires are connected with the same pole of a similar battery. The other poles of the batteries are connected by a wire which returns to the anemometer to the uninsulated binding-serew $\rho$. If more convenient, the return wire may of course be omitted, and the batteries and anemometer be connected to earth.

Let us now suppose the wind is blowing from about Northeast. The trucks H, $\mathrm{K}$ are now on the North and East arms of the cross. The circuit through the South counter is complete from the tongue $\mathrm{Y}$ through the table $\mathrm{O}$, the return wire, the South counter, and then to the South binding-screw $\sigma$ and South insulated rail $\mathrm{R}$; but there it stops, and no current can therefore pass through the South counter. The west circuit is stopped in a similar manner. But in the case of the other circuits, the insulated rail $R$ is in contact with the wheel $Q$, and so through $\mathrm{P}$ the circuit is carried on as far as the tongue Z. Fience in the circuits through the North and East counters a current passes whenever the corresponding tongues $\mathrm{Y}$ and $\mathrm{Z}$ are pressed together, and the corresponding counter marks one.

To determine the value of the readings of the counters, we may resort to measurements of the instrument or to direct experiment. If we place one truck at its furthest distance from the centre and rotate the spindle $B$ a certain number of times, and then note the increase in the reading of the corresponding counter, there will be found a constant ratio $k$ 
Phi1. Mag. S.5.Vol.17. P1. XV

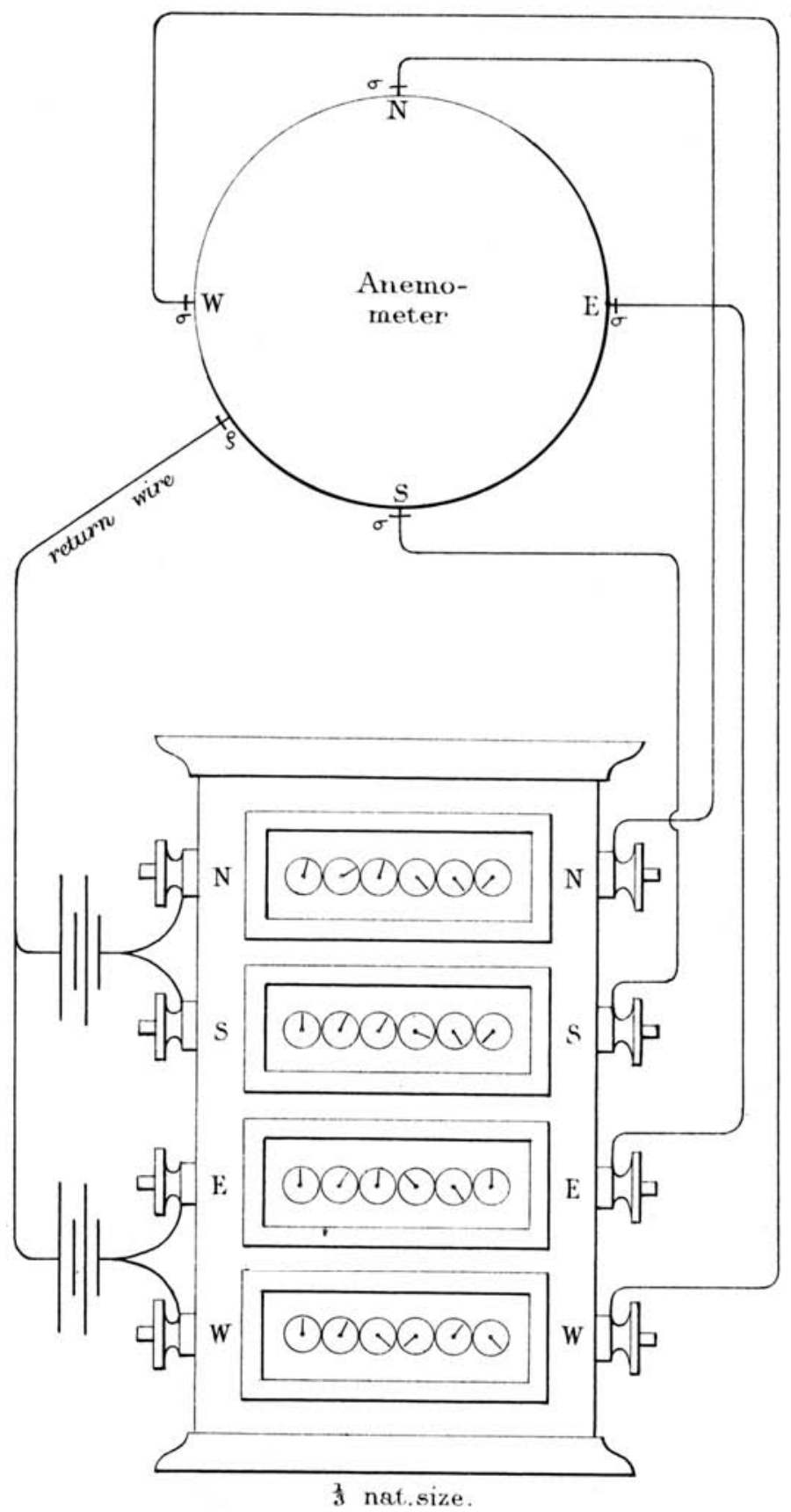

Mintern Brus lith 
between them, so that an increase of $n$ on the counter denotes $k n$ revolutions of $B$.

Letting $\delta$, as before, be the length of the bar $F$ between its points $\mathrm{E}$ (fig. 2), $\delta$ is the greatest distance which the wheel $W$ can go from the centre. Put $\epsilon$ for the radius of $W, \zeta$ for the number of cogs on the edge of the disk $X$, and $\eta$ for the number of cogs on the spindle $B$; we have

$$
\begin{array}{ccc}
\text { Speed of } \mathrm{X}: \text { speed of } \mathrm{B}=\eta: \zeta, \\
", \quad \mathrm{~W}: \quad, \quad \mathrm{X}=\delta: \epsilon, \\
, \quad \mathrm{W}: \quad, \quad \mathrm{B}=\delta \eta: \epsilon \zeta=1: k,
\end{array}
$$

which gives us $k=\frac{\epsilon \zeta}{\delta \eta}$.

If we place the arm $G$ in any other position and turn the spindle $\mathrm{B}$ for some time, and then read $p$ and $q$ as the increase in the readings of the counters of the adjacent cardinal points, the resultant reading for magnitude is $\sqrt{p^{2}+q^{2}}$, and the number of revolutions of $\mathrm{B}$ will be $k \sqrt{p^{2}+q^{2}}$, where $k$ has the same value as before. The direction of the bar $(A$ may be determined by taking $\theta$ as the angle between the bar and the cardinal point to which $p$ relates. Then

whence

$$
p: q=\cos \theta: \sin \theta
$$

$$
\tan \theta=\frac{p}{q}
$$

Of course if B is rotated a certain number of times (say 500), the value of $\sqrt{p^{2}+q^{2}}$ must be the same in whatever position $G$ has been fixed throughout the experiment.

By repeating this experiment with different positions of $G$, we get a means of testing the amount of error to which the instrument is liable.

When the anemometer is connected with a vane and with Robinson's cups, let us suppose the wind to remain in one direction for some time; or, if that cannot be secured, let us either tie up the vane, or disconnect it from the spindle $A$ and fasten the spindle. Let $l$ revolutions of the cups indicate one mile of wind, and $m$ revolutions of the cups give one revolution of the spindle B. Let $p$ and $q$ be the readings of the counters, then the miles of wind indicated will be

$$
k \sqrt{p^{2}+q^{2}} \cdot \frac{l}{m} \text {. }
$$

In ordinary use the bar $G$ will be shifted about in all directions by the wind, and we may have an increase in the readings of all the counters; let these be represented by $n, s, e$, 
$w$ for North, South, East, and West respectively; then the resultant transfer of air during the interval since the last reading will be

$$
k \sqrt{ }\left\{(n-s)^{2}+(e-w)^{2}\right\} \frac{l}{m} ;
$$

and its direction measured from North towards East will be given by the equation

$$
\tan \theta=\frac{e-w}{n-s}
$$

LIV. Notices respecting New Books.

Die physikalischen Grundlagen der Mechanik. Von Dr. HeInricn Streintz. Leipzig: Teubner, 1883.

TT is not an easy matter to characterize this book; for, though the 1 author abjures, in the most defiant manner, all aid from the socalled " Erkenntnisstheorie," it cannot be said that he is always quite free from those metaphysical subtleties which loom so large and mean so little. Yet, on the whole, the genuine physicist shines out, though oceasionally through the clouds of vain imagination. We will therefore confine our remarks to that part, by far the larger part, of the work which is free from this earth-born contamination.

The author's object is to discuss the fundamental laws of Dynamics-what we are accustomed in this country to call Newton's Laws of Motion. But much more than balf of the work is devoted to the First Law, or Gulitei's Principle as it is justly entitled. This discussion is extremely interesting, especially from the historical point of view ; for the author has evidently read much, and is not only always a keen, but usually a really discriminating, critic. His citations from the works of C. Neumann, who is well known as an export mathematician but by no means known as a sound physicist, are to be justified only on the ground that he was a student under that Professor. But his citations from Schell and other authors (or rather, compilers) of little note are quite unnecessary, especially as he has found far higher game in men like Euler, Poisson, Laplace, Lagrange, Kirchboff, and Clerk-Maxwell. There can be little doubt that he has succeeded in showing that each of these men, some of them on more than one occasion, has been guilty of false logic, or, at least, of inconclusive reasoning in parts of the very elements of Dynamics. Those who are curious to find what these errors are, must be referred to the work itself; it is sufficient that we indicate that they are to be found there.

Every one knows the fundamental difficulty which arises when we try to think of absolute, as distinguished from relative, position, velocity, or acceleration. Euler endeavoured to realize the unthinkable, in this case, by a process which virtually amounts to making 